\title{
Revised publishing policy
}

Ctriving to better serve the scientific community and pursue international - consolidation, the Brazilian Oral Research (BOR) has revised its publishing policy. The changes are presented in the Instructions to Authors of the present issue and will come into effect when it is published.

Among the changes, periodicity will now be every two months, thus calling for an increase in the number of articles published, and entailing a reduction in the time spent on reviewing and publishing the articles. Currently, the average time elapsing between acceptance of the submitted manuscript and publication of the article is about 120 days.

Another innovative aspect is the adoption of the abead of print system on the SciELO page. This feature will enable those articles that have been accepted and edited to be available immediately for online consultation and download. This means that the article may be accessed and read even if it has not yet been designated definitively to an issue of the journal. Visit our page on SciELO for further details.

We are also diversifying the types of articles that will be accepted for publication in the BOR, all of which are to beduly assessed by peer-review. Now, in addition to original research articles, the BOR will be accepting short communications, a type of article consisting of an original paper presented concisely, and also systematic reviews and critical literature reviews, as well as relevant clinical cases.

In response to the request of authors, the BOR will now have a Letter to the Editor section, meant to address solely scientific topics about published articles.

The new instructions to authors are available online on the SBPqO and the SciELO pages, and will also be published in the first issue of each volume.

With the aim of improving the quality of the journal, especially in regard to content presentation, all manuscripts approved for publication will be submitted to a technical revision, after which the authors will receive a PDF file that should be checked and approved by them before publication of the manuscript.

In an endeavor to further the policy to bring the BOR closer to its authors and readers, as proposed at the 27th Annual Meeting of the SBPqO, the BOR invites researchers who hold a $\mathrm{PhD}$ and who are proficient in the English language to be reviewers of the journal. Those interested in signing up should send an email tobor@sbpqo.org.br.

We would also like to communicate that, as of the second half of 2011, the entire submission and peer-review process will be carried out online, directly on the SciELO page. For this purpose, we have already started training under the supervision of a specialized SciELO team.

We believe that these changes in the BOR publishing policy will contribute toward achieving scientific and editorial excellence, to ultimately offer the international scientific community Brazil's contribution to dental research.

Nevertheless, we must still increase our citation rate, primarily within the international community; therefore, we urge that you make a point of citing articles published in Brazilian journals in your articles, because we are all responsible for disseminating Brazilian production. We are counting on everyone's participation. 